\title{
The effect of vagal nerve blockade using electrical impulses on glucose metabolism in nondiabetic subjects
}

This article was published in the following Dove Press journal:

Diabetes, Metabolic Syndrome and Obesity: Targets and Therapy

II July 2014

Number of times this article has been viewed

\author{
Matheni Sathananthan' \\ Sayeed Ikramuddin ${ }^{2}$ \\ James M Swain ${ }^{3,6}$ \\ Meera Shah' \\ Francesca Piccinini ${ }^{4}$ \\ Chiara Dalla Man ${ }^{4}$ \\ Claudio Cobelli ${ }^{4}$ \\ Robert A Rizza' \\ Michael Camilleri ${ }^{5}$ \\ Adrian Vella' \\ 'Division of Endocrinology, Diabetes \\ and Metabolism, Mayo Clinic \\ College of Medicine, Rochester, \\ MN, USA; ${ }^{2}$ Division of General \\ Surgery, University of Minnesota, \\ Minneapolis, MN, USA; ${ }^{3}$ Division \\ of General Surgery, Mayo Clinic \\ College of Medicine, Rochester, \\ MN, USA; ${ }^{4}$ Department of \\ Information Engineering, University \\ of Padua, Padua, Italy; ${ }^{5}$ Division of \\ Gastroenterology and Hepatology, \\ Mayo Clinic College of Medicine, \\ Rochester, MN, USA; 'Scottsdale \\ Healthcare Bariatric Center, \\ Scottsdale, AZ, USA
}

Purpose: Vagal interruption causes weight loss in humans and decreases endogenous glucose production in animals. However, it is unknown if this is due to a direct effect on glucose metabolism. We sought to determine if vagal blockade using electrical impulses alters glucose metabolism in humans.

Patients and methods: We utilized a randomized, cross-over study design where participants were studied after 2 weeks of activation or inactivation of vagal nerve blockade (VNB). Seven obese subjects with impaired fasting glucose previously enrolled in a long-term study to examine the effect of VNB on weight took part. We used a standardized triple-tracer mixed meal to enable measurement of the rate of meal appearance, endogenous glucose production, and glucose disappearance. The $550 \mathrm{kcal}$ meal was also labeled with ${ }^{111} \mathrm{In}$-diethylene triamine pentaacetic acid (DTPA) to measure gastrointestinal transit. Insulin action and $\beta$-cell responsivity indices were estimated using the minimal model.

Results: Integrated glucose, insulin, and glucagon concentrations did not differ between study days. This was also reflected in a lack of effect on $\beta$-cell responsivity and insulin action. Furthermore, fasting and postprandial endogenous glucose production, integrated meal appearance, and glucose disposal did not differ in the presence or absence of VNB. Similarly, gastric emptying and colonic transit were unchanged by VNB.

Conclusion: In this pilot study in nondiabetic humans, electrical vagal blockade had no acute effects on glucose metabolism, insulin secretion and action, or gastric emptying. It remains to be determined if more pronounced effects would be observed in diabetic subjects.

Keywords: vagotomy, insulin secretion, insulin action, endogenous glucose production

\section{Introduction}

Bilateral truncal vagotomy results in early satiety and weight loss believed to be, at least in part, due to a decrease in gastric accommodation. ${ }^{1,2}$ Electrical vagal nerve blockade (VNB) for the treatment of refractory epilepsy has also been reported to cause weight loss in some, ${ }^{3,4}$ but not all, ${ }^{5,6}$ case series. When used to treat obesity, electrical blockade of the vagal trunks at the level of the gastric cardia results in decreased caloric intake and significant loss of excess weight in the first 6 months after implantation. ${ }^{7}$ However, weight loss is not sustained 1 year after implantation. ${ }^{8}$

Following vagotomy, adaptive changes in the enteric nervous system, which may include formation of collateral innervation, result in minimal disruption of gastrointestinal function over time. ${ }^{9,10}$ While animal studies suggest that vagal interruption has effects on insulin secretion, ${ }^{11-13}$ insulin action, ${ }^{14}$ and hepatic glucose metabolism, ${ }^{15}$ it presently is unknown if these effects occur in humans following chronic vagal denervation.
Correspondence: Adrian Vella Endocrine Research Unit, Mayo Clinic College of Medicine, 200 First St SW, 5-194 Joseph

Rochester, MN 55905, USA

$\mathrm{Tel}+\mathrm{I} 5072556515$

Fax + I 5072554828

Email vella.adrian@mayo.edu 
The use of chronic, but reversible, ${ }^{16}$ electrical vagal blockade to treat obesity allows direct study of the effect of vagal function on postprandial carbohydrate metabolism and insulin secretion and action independent of changes in weight. In the present experiments we sought to determine if vagal blockade alters $\beta$-cell function and postprandial glucose metabolism. The oral and C-peptide minimal models were utilized as before. ${ }^{17}$ The triple tracer method was used to measure postprandial suppression of glucose production and postprandial stimulation of glucose disposal as well as the rate of the systemic appearance of the ingested glucose. ${ }^{18111}$ In-diethylene triamine pentaacetic acid (DTPA; Mallinckrodt Pharmaceuticals, St. Louis, MO, USA) in the meal enabled measurement of gastric emptying and small intestinal transit. ${ }^{19}$ Subjects were studied on two occasions in random order with VNB activated or inactivated in the 2-week period preceding each experiment. The investigators performing the assays and analyses were blinded until all studies were completed. The primary outcome was an effect of VNB on disposition index (DI) and the secondary outcome was an effect on gastric emptying - specifically the time taken to empty $50 \%$ of gastric contents.

\section{Materials and methods Subjects}

After approval from the Mayo Institutional Review Board, seven nondiabetic subjects gave written, informed consent to participate in the study. These subjects had previously undergone placement of VNB devices as part of a multicenter observational study examining the long-term effects of vagal inhibition ${ }^{7}$ and were weight stable. At the time of recruitment, all participants were actively using their VNB devices on a daily basis for $>12$ months. During the randomized phase of the trial, which ended $>12$ months before recruitment, subjects receiving active treatment experienced a $17 \% \pm 2 \%$ excess weight loss, while those receiving sham treatment lost $16 \% \pm 2 \%$ excess weight. There was no significant difference between groups. ${ }^{8}$ The VNB devices have been described in detail previously - they comprise two electrodes (one for each vagal trunk) placed laparoscopically under general anesthesia, a neuroregulator placed subcutaneously, and an external controller attached to a transmit coil to communicate with and power the device. ${ }^{7}$ Subjects were instructed to wear the device for a minimum of 10 hours daily. When worn, the external controller provides 5 minutes of $5,000 \mathrm{~Hz}$ and an amplitude of $\sim 6 \mathrm{~mA}$ alternating with 5 minutes of no electrical signal. Subjects had no active illness and did not engage in regular vigorous exercise. All subjects were instructed to follow a weight maintenance diet $(-55 \%$ carbohydrate,
$30 \%$ fat, and $15 \%$ protein) for the period of study. Body composition was measured using dual-energy X-ray absorptiometry (DPX scanner; Lunar, Madison, WI, USA). Gastrointestinal symptoms were assessed by the Bowel Disease Questionnaire. ${ }^{20}$

\section{Experimental design}

Subjects were studied using a labeled mixed meal and were randomized to either continue vagal blockade for 2 weeks or to discontinue vagal blockade for 2 weeks. A mixed meal study was then undertaken and subjects crossed over to resume vagal blockade in one group and discontinue blockade in the other. A mixed meal was repeated after the second 2-week period. The trial was registered at http://www. clinicaltrials.gov (NCT01117311).

Participants were admitted to the Clinical Research Unit at $5 \mathrm{pm}$ the night before the study, consumed a standardized low-calorie mixed meal (400 Kcal: 55\% carbohydrate, 30\% fat, and $15 \%$ protein), after which they fasted overnight. At 6 am (-180 minutes), a forearm vein was cannulated with an 18 gauge needle to allow infusions to be performed. An 18 gauge cannula was inserted retrogradely into a vein of the dorsum of the contralateral hand. This was placed in a heated Plexiglas box (Department of Biomedical Engineering, Mayo Clinic Rochester, MN, USA) maintained at $55^{\circ} \mathrm{C}$ to allow sampling of arterialized venous blood. A primed $(12 \mathrm{mg} / \mathrm{kg})$ continuous $(0.12 \mathrm{mg} / \mathrm{kg} / \mathrm{min})$ infusion of $\left[6,6-{ }^{2} \mathrm{H}_{2}\right]$ glucose (PerkinElmer Life Sciences, Waltham, MA, USA) was initiated. At 9 am (0 minutes), subjects consumed a meal consisting of two scrambled eggs, $50 \mathrm{~g}$ of Canadian bacon and Jell-O containing $70 \mathrm{~g}$ of glucose labeled with $\left[1-{ }^{13} \mathrm{C}\right]$ ( $4 \%$ enrichment). This meal provided $510 \mathrm{kcal}$ (61\% carbohydrate, 19\% protein, and 21\% fat). To enable measurement of solid phase gastric emptying, the egg was labeled with $0.1 \mathrm{mCi}{ }^{111} \mathrm{In}-D T P A$. An infusion of $\left[6-{ }^{3} \mathrm{H}\right]$ glucose was started at this time, and the infusion rate varied to mimic the anticipated appearance of meal $\left[1-{ }^{13} \mathrm{C}\right]$ glucose. The rate of infusion of $\left[6,6-{ }^{2} \mathrm{H}_{2}\right]$ glucose was altered to approximate the anticipated fall in endogenous glucose production (EGP) thereby minimizing changes in specific activity. ${ }^{21,22}$

Gastrointestinal transit was measured by anterior and posterior gamma camera images obtained immediately after meal ingestion, every 15 minutes for the first 2 hours, then every 30 minutes for the next 2 hours (total 4 hours after the meal) for gastric emptying measurements. To evaluate orocecal transit, scintigraphy was repeated 6 and 24 hours after meal ingestion so as to quantitate and localize the remaining ${ }^{111} \mathrm{In}$ in the intestine using a single scan of the gamma camera. To locate the cecum, a radioisotope marker was placed on the 
patient's right anterior superior iliac spine. ${ }^{19}$ Overall colonic transit was analyzed using the geometric center method, where the weighted average of counts in four colonic regions (ascending, transverse, descending, and rectosigmoid) and stool was estimated by quantifying the isotopic counts in each of these regions, and correcting for isotope decay. A score of 1 reflects the average position of isotope at the hepatic flexure, 2 at the splenic flexure, 3 at the junction of the descending and sigmoid, 4 at the anal canal, and 5 in the stool. ${ }^{19}$

\section{Analytical techniques and glucose turnover}

Plasma samples were placed on ice, centrifuged at $4^{\circ} \mathrm{C}$, separated, and stored at $-20^{\circ} \mathrm{C}$ until assayed. Glucose concentrations were measured using a glucose oxidase method (Yellow Springs Instruments, Yellow Springs, OH, USA). Plasma insulin was measured using a chemiluminescence assay (Access Assay; Beckman Coulter, Chaska, MN, USA). Plasma glucagon and C-peptide were measured by Radio-Immunoassay (EMD Millipore, Billerica, MA, USA). Plasma $\left[6,6-{ }^{2} \mathrm{H}_{2}\right]$ glucose and $\left[1-{ }^{13} \mathrm{C}\right]$ glucose enrichments were measured using gas chromatographic mass spectrometry (Thermoquest, San Jose, CA, USA) to simultaneously monitor the C-1 and C-2 and C-3 to C-6 fragments, as described by Beylot et al. ${ }^{23}$ In addition, $\left[6-{ }^{3} \mathrm{H}\right]$ glucose specific activity was measured by liquid scintillation counting following deproteinization and passage over anion and cation exchange columns. ${ }^{22}$

\section{Calculations}

The systemic rates of meal appearance $\left(\mathrm{Ra}_{\text {meal }}\right)$, EGP, and glucose disappearance were calculated using Steele's two compartment model. ${ }^{24} \mathrm{Ra}_{\text {meal }}$ was calculated by multiplying rate of appearance of $\left[1-{ }^{13} \mathrm{C}\right]$ glucose (obtained from the infusion rate of $\left[6-{ }^{3} \mathrm{H}\right]$ glucose and the clamped plasma ratio of $\left[6-{ }^{3} \mathrm{H}\right]$ glucose and $\left[1-{ }^{13} \mathrm{C}\right]$ glucose) by the meal enrichment. EGP was calculated from the infusion rate of $\left[6,6-{ }^{2} \mathrm{H}_{2}\right]$ glucose and the ratio of $\left[6,6-{ }^{2} \mathrm{H}_{2}\right]$ glucose to endogenous glucose concentration. Glucose disappearance was calculated by subtracting the change in glucose mass from the overall rate of glucose appearance (ie, $\mathrm{Ra}_{\text {meal }}+$ EGP + infused $\left[6,6-{ }^{2} \mathrm{H}_{2}\right]$ glucose). Values from -30 to 0 minutes were averaged and considered as basal. Area under the curve was calculated using the trapezoidal rule.

\section{Measurement of insulin secretion and action}

Net insulin action $\left(S_{\mathrm{I}}\right)$ was measured using the oral minimal model, which estimates insulin action from the changes in glucose and insulin concentrations during the meal challenge. ${ }^{25}$ The methodology underlying the oral minimal model has been the subject of a recent review. ${ }^{26}$ Modeling the response to an oral challenge allows simultaneous measurement of insulin secretion and action, as well as the extraction of portal insulin by the liver prior to appearing in the systemic circulation. $\beta$-Cell responsivity indices were estimated using the oral $\mathrm{C}$-peptide minimal model, utilizing the changes in glucose and C-peptide concentrations during the meal challenge. ${ }^{27}$ Insulin secretion is obtained from C-peptide concentrations by a process of deconvolution, which incorporates age-associated changes in C-peptide kinetics. ${ }^{28} \mathrm{An}$ index of total beta-cell responsivity to glucose $\left(\phi_{\text {total }}\right)$ is derived subsequently. ${ }^{29}$ DI were calculated by multiplying $\phi_{\text {total }}$ by $S_{\mathrm{I}}$. Hepatic extraction was calculated from the ratio of peripheral insulin to portal insulin (as calculated from C-peptide) as previously described..$^{30}$

\section{Statistical analysis}

Data in the text are presented as means \pm standard error of the mean (SEM). The primary analysis compared data obtained during the meal study where vagal blockade was activated in the 2 weeks prior to study (VNB on) or inactivated in the 2 weeks prior to study (VNB off). A Wilcoxon matchedpairs signed rank test (two-tailed), which does not assume Gaussian distribution, was used to test the significance of the changes of study variables between study days. The statistical analysis was undertaken in Primer $5(\mathrm{GraphPad}$ Software, Inc., La Jolla, CA, USA). A $P$-value $<0.05$ was considered statistically significant.

\section{Results Volunteer characteristics}

Seven of nine subjects (all female) participating at Mayo Clinic, Rochester, MN or University of Minnesota, Minneapolis, $\mathrm{MN}$ in the observation phase of the EMPOWER study ${ }^{8}$ gave written, informed consent to participate in the study. The remaining two subjects declined to participate in this study. The study participants' mean age was $53.1 \pm 1.8$ years. At the time of screening, weight was $104 \pm 5 \mathrm{~kg}$, body mass index (BMI) was $37.3 \pm 1.2 \mathrm{~kg} / \mathrm{m}^{2}$ and lean body mass was $49 \pm 6 \mathrm{~kg}$. The VNB device was interrogated at the time of each study visit to ensure appropriate duration of use, and proper function, over the 2-week interval preceding each study. Subjects enrolled in the study were at stable weight, and did not have significant gastrointestinal symptoms as measured by the Bowel Disease Questionnaire. ${ }^{20}$ 
Plasma glucose, insulin, C-peptide, and glucagon concentrations in the presence or absence of vagal nerve blockade

Fasting glucose $(6.3 \pm 0.6$ versus [vs] $6.1 \pm 0.6 \mathrm{mmol} / \mathrm{L}, P=0.11)$ just prior to meal ingestion did not differ when VNB was pres-
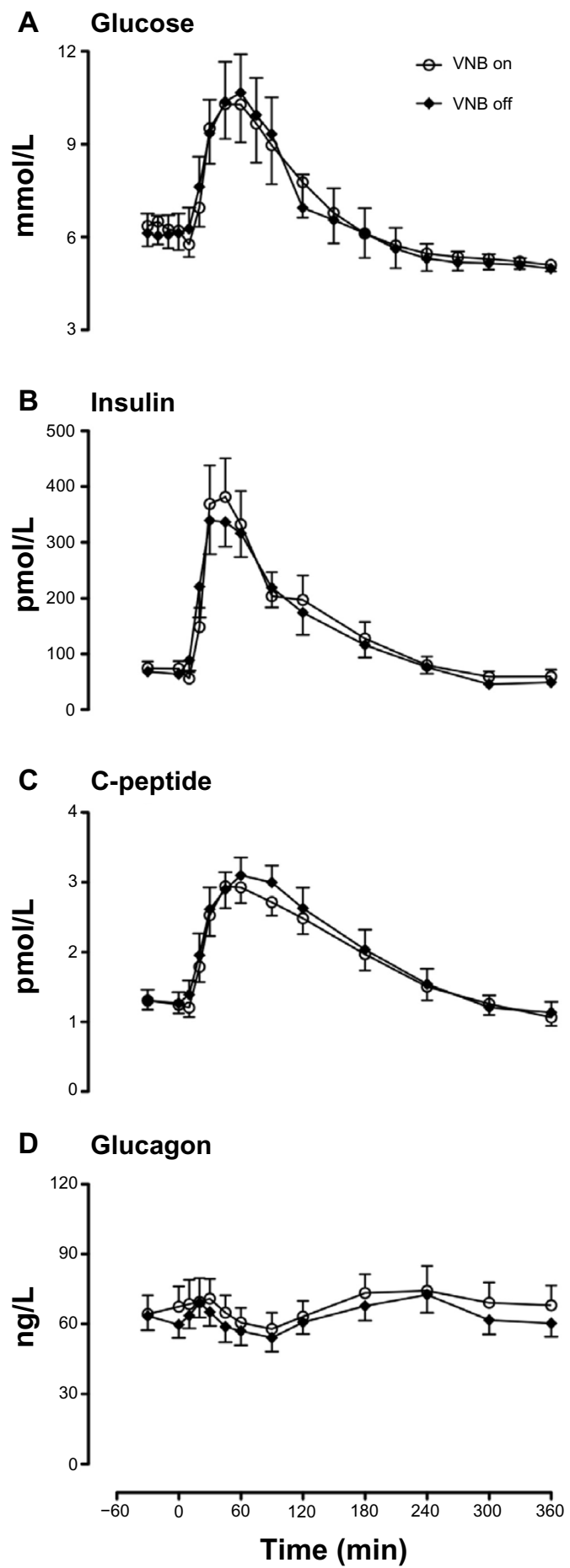

Figure I Glucose (A), insulin (B), C-peptide (C) and glucagon (D) concentrations in the presence (white open circle) or absence of VNB (solid black diamond). Abbreviations: min, minute; VNB, vagal nerve blockade. ent or absent, respectively (Figure 1). Postmeal peak (10.7 \pm 1.2 vs $10.9 \pm 1.2 \mathrm{mmol} / \mathrm{L}, P=0.55)$ and integrated postprandial glucose concentrations $(2,430 \pm 260$ vs $2,440 \pm 260 \mathrm{mmol}$ per 6 hours, $P=1.00$ ) did not differ in the presence or absence of VNB (Figure 1A).

Fasting ( $74 \pm 12$ vs $66 \pm 10 \mathrm{pmol} / \mathrm{L}, P=0.16)$, postmeal peak insulin concentrations ( $412 \pm 69 \mathrm{vs} 426 \pm 53 \mathrm{pmol} / \mathrm{L}, P=0.69)$ as well as integrated postprandial insulin concentrations (53.4 \pm 9.0 vs $50.0 \pm 6.5 \mathrm{nmol} / \mathrm{L}$ per 6 hours, $P=0.69$ ) did not differ in the presence or absence of vagal blockade (Figure 1B).

Fasting $(1.3 \pm 0.1$ vs $1.3 \pm 0.2 \mathrm{nmol} / \mathrm{L}, P=0.85)$ and postprandial $(3.2 \pm 0.2 \mathrm{vs} 3.2 \pm 0.3 \mathrm{nmol} / \mathrm{L}, P=0.62) \mathrm{C}$-peptide concentrations (Figure 1C) and fasting ( $66 \pm 8$ vs $62 \pm 6 \mathrm{ng} / \mathrm{L}$, $P=0.25)$, peak ( $82 \pm 9$ vs $76 \pm 7 \mathrm{ng} / \mathrm{L}, P=0.22)$, and nadir (55 \pm 7 vs $53 \pm 6 \mathrm{ng} / \mathrm{L}, P=0.85)$ postprandial glucagon concentrations also did not differ in the presence or absence of vagal blockade (Figure 1D).

\section{Endogenous glucose production, meal appearance, and glucose disappearance in the presence or absence of vagal nerve blockade}

Fasting glucose production (Figure 2A) was unchanged by vagal blockade ( $15.4 \pm 0.9$ vs $15.2 \pm 1.1 \mu \mathrm{mol} / \mathrm{kg} / \mathrm{min}, P=0.48)$. Similarly, postprandial suppression of glucose production by meal ingestion was not altered by vagal blockade $(4.7 \pm 0.4$ vs $4.5 \pm 0.3 \mu \mathrm{mol} / \mathrm{kg} / \mathrm{min}, P=0.14)$.

The rate of appearance of ingested glucose did not differ in the presence or absence of vagal blockade (Figure $2 \mathrm{~B}$ ) in terms of peak rate of appearance ( $46 \pm 3$ vs $55 \pm 8 \mu \mathrm{mol} / \mathrm{kg} / \mathrm{min}$, $P=0.35)$, time to peak ( $31 \pm 3$ vs $28 \pm 4$ minutes, $P=0.60)$ and integrated total rate of appearance $(3,407 \pm 122$ vs $3,802 \pm 257 \mu \mathrm{mol}$ per 6 hours, $P=0.26$ ).

Postprandial peak rate of glucose disposal (Figure 2C) ( $50 \pm 3 \mathrm{vs} 60 \pm 8 \mu \mathrm{mol} / \mathrm{kg} / \mathrm{min}, P=0.24)$, and integrated rate of postprandial glucose disposal did not differ in the presence or absence of vagal blockade $(6,315 \pm 137$ vs $6,601 \pm 304 \mu \mathrm{mol}$ per 6 hours, $P=0.47$ ).

\section{Insulin action, $\beta$-cell responsivity, disposition index, and hepatic extraction of insulin in the presence or absence of vagal nerve blockade} Insulin action (Figure 3A: $7.9 \pm 2.7$ vs $6.5 \pm 1.210^{-4} \mathrm{dL} / \mathrm{kg} / \mathrm{min}$ per $\mu \mathrm{U} / \mathrm{mL}, P=0.81), \beta$-cell responsivity $\left(\phi_{\text {total }}\right.$, Figure $3 \mathrm{~B}$ : $56 \pm 15$ vs $47 \pm 810^{-9} \mathrm{~min}^{-1}, P=0.58$ ), DI (Figure $3 \mathrm{C}$ : $713 \pm 240$ vs $532 \pm 14510^{-14} \mathrm{dL} / \mathrm{kg} / \mathrm{min}^{2}$ per $\mathrm{pmol} / \mathrm{L}, P=0.30$ ) 


\section{A Endogenous glucose production}
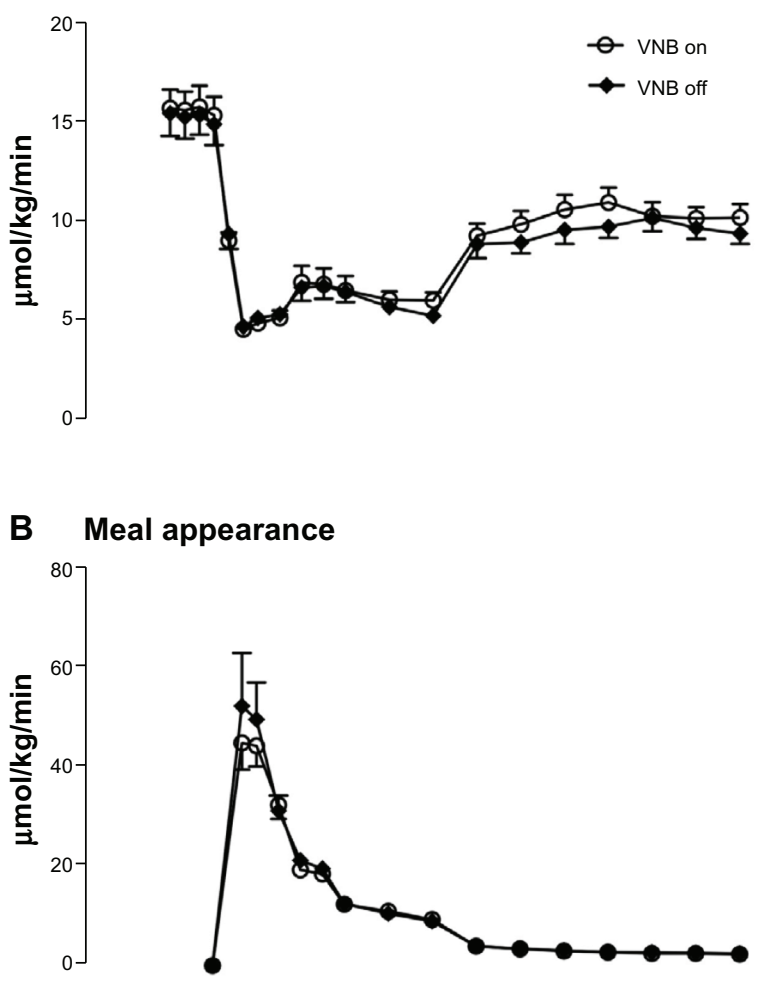

C Glucose disappearance

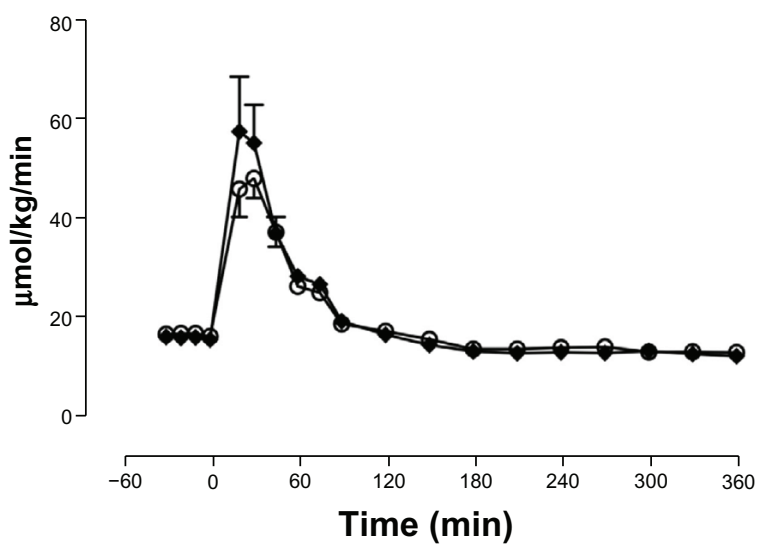

Figure 2 Endogenous glucose production (A), meal appearance (B), and glucose disappearance $(\mathbf{C})$ in the presence (white open circle) or absence of VNB (solid black diamond).

Abbreviations: min, minute; VNB, vagal nerve blockade.

and hepatic extraction of insulin (Figure 3D: $0.41 \pm 0.06$ vs $0.45 \pm 0.03, P=0.47$ ) did not differ in the presence and absence of VNB.

\section{Gastric emptying in the presence or absence of vagal nerve blockade}

The fraction of the solid meal retained within the stomach did not differ at any time point in the presence or absence of

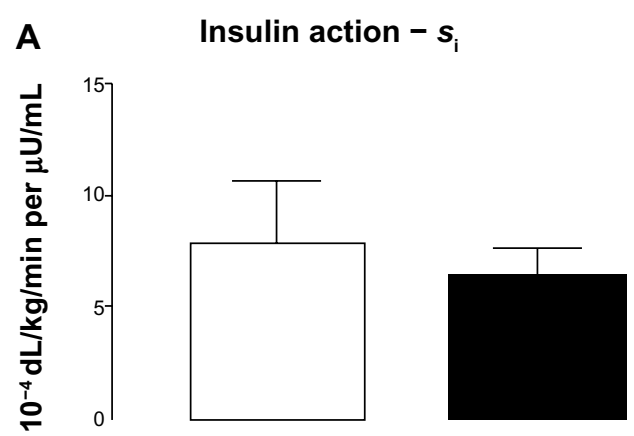

B $\quad \beta$-cell responsivity $-\phi_{\text {total }}$
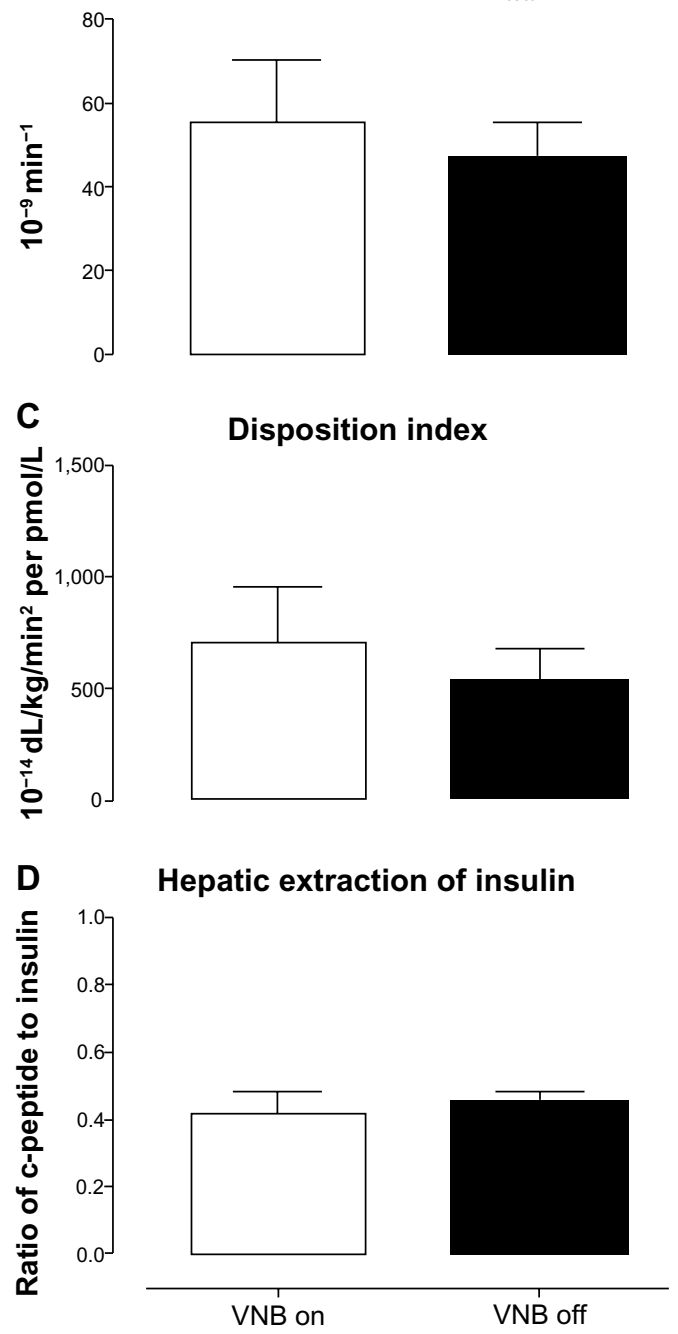

Figure 3 Insulin action $\left(S_{i}, \mathbf{A}\right), \beta$-cell responsivity $\left(\phi_{\text {total, }}\right.$ B), disposition indices $(\mathbf{C})$, and hepatic extraction of insulin (D) concentrations in the presence (white open column) or absence of VNB (solid black column).

Abbreviations: min, minute; VNB, vagal nerve blockade.

vagal blockade. Similarly, the time taken to empty $50 \%$ of gastric contents ( $160 \pm 15$ vs $160 \pm 23$ minutes, $P=0.53$ ) did not differ (Figure 4). Colonic transit at 24 hours was unchanged $(2.16 \pm 0.38$ vs $2.39 \pm 0.44, P=1.00)$ in the presence or absence of vagal blockade. 


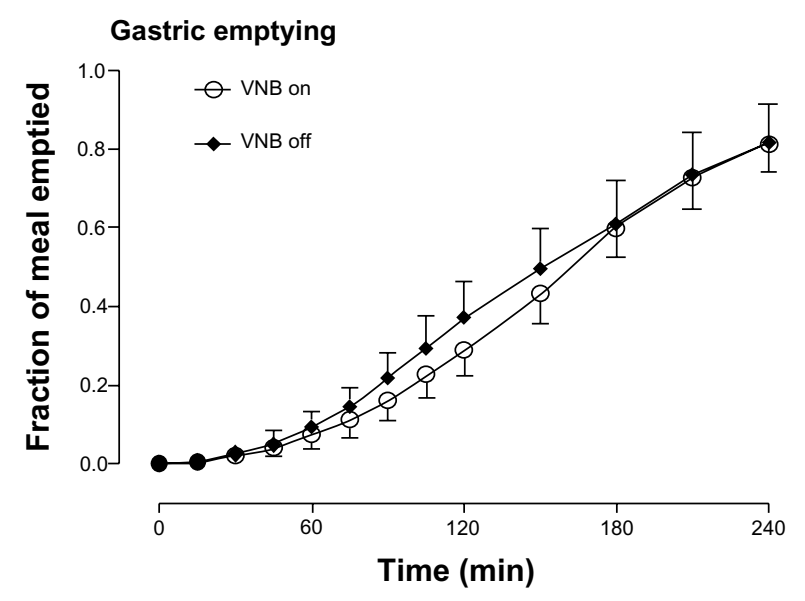

Figure 4 Gastric emptying in the presence (white open circle) or absence of VNB (solid black diamond).

Abbreviations: min, minute; VNB, vagal nerve blockade.

\section{Discussion}

The effect of vagal interruption on glucose metabolism in humans has been an area of uncertainty. We report that VNB, previously shown to reversibly block $\mathrm{A} \delta$ and $\mathrm{C}$ components of vagal compound action potentials, ${ }^{31}$ does not alter fasting and postprandial glucose, insulin, and glucagon concentrations. There were also no effects on fasting and postprandial glucose metabolism. Consequently, we conclude that in obese, nondiabetic humans, vagal blockade has no effect on insulin secretion and action or on glucose metabolism.

The vagus nerve comprises both efferent cholinergic fibers, which mediate secretomotor responses, and afferent fibers that transmit sensory impulses from chemoreceptors and mechanoreceptors distributed throughout the intestine. Preclinical studies in animals have suggested an effect of vagal blockade on both afferent and efferent impulse transmission. ${ }^{16,31}$ Of note, surgical interruption of the vagus nerve is usually associated with some degree of remodeling, which can result in reformation of afferent but not efferent pathways. ${ }^{10}$ Whether this can explain the diminishing effect of vagal blockade on weight loss over time is, at present, unresolved. ${ }^{7,8}$ The participants in this study did not report the presence of bowel symptoms at the time of screening in response to the validated bowel disease questionnaire ${ }^{20}$ suggesting some degree of adaptation to vagal blockade. This is consistent with the prior observation of normal gastric accommodation in asymptomatic subjects with chronic diabetic vagal neuropathy. ${ }^{32}$

The absence of an effect of chronic VNB on basal glucose production contrasts with the effect of acute vagal cooling on hepatic glucose production in dogs which produced an $\sim 20 \%$ decrease in fasting glucose production. ${ }^{15}$ Our current sample size may have precluded detection of an effect of similar magnitude on glucose production, although we had greater than $80 \%$ power to detect a $25 \%$ change in fasting EGP. Effects of vagal interruption on canine hepatic glucose metabolism have not been observed in the presence of hyperinsulinemia and hyperglycemia. ${ }^{33}$ Such conditions - similar to those during the postprandial period - maximally stimulate hepatic glucose uptake and suppress hepatic glucose production, implying that any potential effect on glucose metabolism is overcome by the effects of postprandial glucose and insulin concentrations. This would be congruent with our observations in the postprandial period. No effect on systemic meal appearance or peripheral glucose disposal was observed. In this experiment, direct measurement of gastric emptying of the solid phase of the meal also did not demonstrate an effect of vagal blockade on solid gastric emptying, again suggesting that the enteric nervous system can compensate for vagotomy or vagal blockade. ${ }^{10,32}$

Our studies were conducted after conclusion of the randomized phase of the original study of the effect of vagal blockade on weight loss, when all subjects were treated with electrical vagal blockade and had been using the activated device for more than a year. It is possible that the same mechanisms that lead to tachyphylaxis after vagotomy obscure any potential effects on glucose metabolism. Given the small sample size available for study, it is conceivable that we were underpowered to detect a small effect of VNB on glucose metabolism. However, in the present experiments it is important to observe the near identical glucose concentrations in the presence or absence of VNB so that with the observed variance in glucose concentrations, $>100$ subjects would be required to detect a $10 \%$ change in glucose concentrations with vagal blockade. Such an effect size would be unlikely to be of clinical significance, especially when compared to other pharmacologic interventions and their effect on glycemic control. ${ }^{34}$

It is also possible that a beneficial effect on glucose metabolism, and more specifically $\beta$-cell function, is more difficult to demonstrate in nondiabetic individuals who despite impaired fasting glucose have relatively intact insulin secretory capabilities compared to people with type 2 diabetes, ${ }^{35}$ and future studies would need to be conducted in diabetic patients. Indeed, a more recent study in 26 subjects with type 2 diabetes using a similar device and electrical algorithms achieved sustained weight loss over a 1-year period, together with improved $\mathrm{HbA}_{1 \mathrm{c}}$, fasting glucose, and blood pressure. ${ }^{36}$ While encouraging, this study did not include a control group. 
Moreover, the study design does not allow ascertainment of whether there is a direct effect of vagal blockade on glucose metabolism or whether the metabolic effects are dependent on the weight loss observed in subjects with type 2 diabetes.

We conclude that in the short-term, inactivation of vagal blockade over 1 year after initial implantation has little effect on glucose metabolism and insulin secretion. While this study does not preclude a small effect of vagal blockade on glucose metabolism that is independent of weight loss, such an effect is unlikely to be of clinical significance in nondiabetic subjects.

\section{Acknowledgments}

This work is supported by National Institutes of Health grant numbers DK82396 and DK50456. The authors acknowledge the support of the Mayo Clinic General Clinical Research Center (funded by TR000135). Dr Vella and Dr Cobelli are supported by DK78646 and by DK82396.

\section{Author contributions}

All authors contributed toward data analysis, drafting and revising the paper and agree to be accountable for all aspects of the work.

\section{Disclosure}

Dr Vella has received research grants from Merck and Daiichi-Sankyo. He has consulted for Sanofi-Aventis, Novartis, and Bristol-Myers Squibb. Dr Camilleri has served as a consultant for Enteromedics. The other authors report no conflicts of interest in this work.

\section{References}

1. Smith DK, Sarfeh J, Howard L. Truncal vagotomy in hypothalamic obesity. Lancet. 1983;1(8337):1330-1331.

2. Kral JG, Paez W, Wolfe BM. Vagal nerve function in obesity: therapeutic implications. World J Surg. 2009;33(10):1995-2006.

3. Abubakr A, Wambacq I. Long-term outcome of vagus nerve stimulation therapy in patients with refractory epilepsy. J Clin Neurosci. 2008;15(2):127-129.

4. Burneo JG, Faught E, Knowlton R, Morawetz R, Kuzniecky R. Weight loss associated with vagus nerve stimulation. Neurology. 2002;59(3):463-464.

5. Kansagra S, Ataya N, Lewis D, Gallentine W, Mikati MA. The effect of vagus nerve stimulation therapy on body mass index in children. Epilepsy Behav. 2010;19(1):50-51.

6. Koren MS, Holmes MD. Vagus nerve stimulation does not lead to significant changes in body weight in patients with epilepsy. Epilepsy Behav. 2006;8(1):246-249.

7. Camilleri M, Toouli J, Herrera MF, et al. Intra-abdominal vagal blocking (VBLOC therapy): clinical results with a new implantable medical device. Surgery. 2008;143(6):723-731.

8. Sarr MG, Billington CJ, Brancatisano R, et al; EMPOWER Study Group. The EMPOWER study: randomized, prospective, double-blind, multicenter trial of vagal blockade to induce weight loss in morbid obesity. Obes Surg. 2012;22(11):1771-1782.
9. Takahashi T, Owyang C. Characterization of vagal pathways mediating gastric accommodation reflex in rats. J Physiol. 1997; 504(Pt 2):479-488.

10. Li Y, Owyang C. Musings on the wanderer: what's new in our understanding of vago-vagal reflexes? V. Remodeling of vagus and enteric neural circuitry after vagal injury. Am J Physiol Gastrointest Liver Physiol. 2003;285(3):G461-G469.

11. Ruiz de Azua I, Gautam D, Jain S, Guettier JM, Wess J. Critical metabolic roles of $\beta$-cell M3 muscarinic acetylcholine receptors. Life Sci. 2012;91(21-22):986-991.

12. Ahrén B, Holst JJ. The cephalic insulin response to meal ingestion in humans is dependent on both cholinergic and noncholinergic mechanisms and is important for postprandial glycemia. Diabetes. 2001;50(5): 1030-1038.

13. Nishi S, Seino Y, Ishida H, et al. Vagal regulation of insulin, glucagon, and somatostatin secretion in vitro in the rat. J Clin Invest. 1987;79(4): 1191-1196.

14. Latour MG, Lautt WW. The hepatic vagus nerve in the control of insulin sensitivity in the rat. Auton Neurosci. 2002;95(1-2):125-130.

15. Cardin S, Walmsley K, Neal DW, Williams PE, Cherrington AD Involvement of the vagus nerves in the regulation of basal hepatic glucose production in conscious dogs. Am J Physiol Endocrinol Metab. 2002;283(5):E958-E964.

16. Camilleri M, Toouli J, Herrera MF, et al. Selection of electrical algorithms to treat obesity with intermittent vagal block using an implantable medical device. Surg Obes Relat Dis. 2009;5(2):224-229; discussion 229-230.

17. Dalla Man C, Campioni M, Polonsky KS, et al. Two-hour seven-sample oral glucose tolerance test and meal protocol: minimal model assessment of beta-cell responsivity and insulin sensitivity in nondiabetic individuals. Diabetes. 2005;54(11):3265-3273.

18. Vella A, Rizza RA. Application of isotopic techniques using constant specific activity or enrichment to the study of carbohydrate metabolism. Diabetes. 2009;58(10):2168-2174.

19. Cremonini F, Mullan BP, Camilleri M, Burton DD, Rank MR. Performance characteristics of scintigraphic transit measurements for studies of experimental therapies. Aliment Pharmacol Ther. 2002;16(10):1781-1790.

20. Talley NJ, Phillips SF, Melton J 3rd, Wiltgen C, Zinsmeister AR. A patient questionnaire to identify bowel disease. Ann Intern Med. 1989;111(8):671-674.

21. Bock G, Dalla Man C, Micheletto F, et al. The effect of DPP-4 inhibition with sitagliptin on incretin secretion and on fasting and postprandial glucose turnover in subjects with impaired fasting glucose. Clin Endocrinol (Oxf). 2010;73(2):189-196.

22. Dalla Man C, Bock G, Giesler PD, et al. Dipeptidyl peptidase-4 inhibition by vildagliptin and the effect on insulin secretion and action in response to meal ingestion in type 2 diabetes. Diabetes Care. 2009;32(1): 14-18.

23. Beylot M, Previs SF, David F, Brunengraber H. Determination of the 13C-labeling pattern of glucose by gas chromatography-mass spectrometry. Anal Biochem. 1993;212(2):526-531.

24. Steele R, Bjerknes C, Rathgeb I, Altszuler N. Glucose uptake and production during the oral glucose tolerance test. Diabetes. 1968;17(7):415-421.

25. Dalla Man C, Caumo A, Basu R, Rizza R, Toffolo G, Cobelli C. Measurement of selective effect of insulin on glucose disposal from labeled glucose oral test minimal model. Am J Physiol Endocrinol Metab. 2005;289(5):E909-E914.

26. Cobelli C, Dalla Man C, Toffolo G, Basu R, Vella A, Rizza R. The oral minimal model method. Diabetes. 2014;63(4):1203-1213.

27. Breda E, Cavaghan MK, Toffolo G, Polonsky KS, Cobelli C. Oral glucose tolerance test minimal model indexes of beta-cell function and insulin sensitivity. Diabetes. 2001;50(1):150-158.

28. Van Cauter E, Mestrez F, Sturis J, Polonsky KS. Estimation of insulin secretion rates from C-peptide levels. Comparison of individual and standard kinetic parameters for C-peptide clearance. Diabetes. 1992;41(3):368-377. 
29. Cobelli C, Dalla Man C, Sparacino G, Magni L, De Nicolao G, Kovatchev BP. Diabetes: models, signals, and control. IEEE Rev Biomed Eng. 2009;2:54-96.

30. Campioni M, Toffolo G, Basu R, Rizza RA, Cobelli C. Minimal model assessment of hepatic insulin extraction during an oral test from standard insulin kinetic parameters. Am J Physiol Endocrinol Metab. 2009;297(4):E941-E948.

31. Waataja JJ, Tweden KS, Honda CN. Effects of high-frequency alternating current on axonal conduction through the vagus nerve. J Neural Eng. 2011;8(5):056013.

32. Delgado-Aros S, Vella A, Camilleri M, et al. Effects of glucagon-like peptide-1 and feeding on gastric volumes in diabetes mellitus with cardio-vagal dysfunction. Neurogastroenterol Motil. 2003;15(4): 435-443.
33. DiCostanzo CA, Dardevet DP, Williams PE, et al. The effect of vagal cooling on canine hepatic glucose metabolism in the presence of hyperglycemia of peripheral origin. Metabolism. 2007;56(6): 814-824.

34. Azuma K, Rádiková Z, Mancino J, et al. Measurements of islet function and glucose metabolism with the dipeptidyl peptidase 4 inhibitor vildagliptin in patients with type 2 diabetes. J Clin Endocrinol Metab. 2008;93(2):459-464.

35. Dalla Man C, Micheletto F, Sathananthan A, Rizza RA, Vella A, Cobelli C. A model of GLP-1 action on insulin secretion in nondiabetic subjects. Am J Physiol Endocrinol Metab. 2010;298(6): E1115-E1121.

36. Shikora S, Toouli J, Herrera MF, et al. Vagal blocking improves glycemic control and elevated blood pressure in obese subjects with type 2 diabetes mellitus. J Obes. 2013;2013:245683.

\section{Publish your work in this journal}

Diabetes, Metabolic Syndrome and Obesity: Targets and Therapy is an international, peer-reviewed open-access journal committed to the rapid publication of the latest laboratory and clinical findings in the fields of diabetes, metabolic syndrome and obesity research. Original research, review, case reports, hypothesis formation, expert opinion and commentaries are all considered for publication. The manuscript management system is completely online and includes a very quick and fair peer-review system, which is all easy to use. Visit http://www.dovepress.com/testimonials.php to read real quotes from published authors.

Submit your manuscript here: http://www.dovepress.com/diabetes-metabolic-syndrome-and-obesity-targets-and-therapy-journal 